\title{
O RESSENTIMENTO EM DOM CASMURRO
}

\section{VITOR CEI}

Universidade Federal do Espírito Santo

Espírito Santo, Vitória, Brasil

Resumo: O objetivo geral deste artigo é argumentar que o narrador-protagonista do romance Dom Casmurro é um "homem do ressentimento". Como objetivo específico, avalia como essa temática, abordada por Nietzsche em Genealogia da moral, ressignificou-se na obra de Machado de Assis. Embora o ressentimento de Bento Santiago apresente várias afinidades eletivas com o conceito nietzschiano, ele estrutura-se a partir de questões machadianas específicas, como o ciúme e o prazer das dores velhas.

Palavras-chave: Machado de Assis; Dom Casmurro; Nietzsche; ressentimento.

\section{DOM CASMURRO ON RESENTMENT}

Abstract: The main purpose of this paper is to argue that the main character and narrator of Dom Casmurro is a "man of resentment". The specific objective is to analyse how this topic, approached by Nietzsche in the book On the Genealogy of Morality, was resignified in Machado's work. Although Bento Santiago's resentment has elective affinities with Nietzsche's concept, its structure is based on specific Machadian issues, such as jealousy and pleasure in old sufferings.

Keywords: Machado de Assis; Dom Casmurro; Nietzsche; resentment.

É conhecido o pendor do narrador casmurro pela exageração e supervalorização dos próprios sentimentos. Bento Santiago é um desses lunáticos machadianos que se entregam a uma ideia fixa - no caso o ciúme - como a única chave para o entendimento de tudo. O seu antecessor, Brás Cubas, já alertava que uma ideia fixa leva a uma obstrução 
na visão, sendo mais grave do que um cisco no olho: "Deus te livre, leitor, de uma ideia fixa; antes um argueiro, antes uma trave no olho". ${ }^{1}$

Em Genealogia da moral, Nietzsche endossa o alerta do defunto autor, ao explicar que o sistema nervoso e intelectual fica hipnotizado por essas "ideias fixas", indeléveis, onipresentes e inesquecíveis, de tal modo que a pessoa com ideia fixa torna-se escrava de seus próprios afetos e de sua crença despótica. $^{2}$

O ciúme e o ressentimento, isto é, a vontade de Bento de tornar Capitu culpada, até ser impossível a expiação, sua vontade de vê-la castigada, sem que o castigo possa jamais equivaler à culpa, sua vontade de infectar e envenenar todo o fundo das coisas com o problema do castigo e da culpa, o impedem de ter uma visão lúcida da realidade. Não obstante, como o leitor familiarizado com a fortuna crítica já sabe, até a publicação de O Otelo brasileiro de Machado de Assis (1960), de Helen Caldwell, os leitores de Dom Casmurro acreditaram cegamente na versão do narrador, condenando Capitu por unanimidade. "A desconfiança de Santiago em relação a Capitu é a urdidura de sua narrativa", 3 avalia Caldwell. Na mesma sintonia, Silviano Santiago alerta para não cairmos no equívoco da crítica enferrujada que insiste em analisar Dom Casmurro como um estudo psicológico do adultério feminino: "se estudo for, é antes estudo do ciúme, e apenas deste". ${ }^{4}$

Considerando que o tema do ciúme já foi exaustivamente estudado e que está fora de dúvida que Bento escreve a sua história com a finalidade de condenar Capitu, este artigo é dedicado a avaliar como esse estado emocional que envolve um sentimento penoso provocado pelo receio de que o ente amado dedique seu afeto a outrem conduziu o narrador-protagonista ao ressentimento.

Silviano Santiago avalia que o problema do ciúme no universo machadiano advém, por um lado, da concepção que os personagens de seus romances têm do que sejam o amor e o casamento, e, por outro, dos papéis sociais que homens e mulheres têm de representar para poderem chegar à união conjugal:

Assinalávamos de início como o conceito de casamento restringe a expansão livre do sentimento, pois o amor é um sentimento enjaulado pela cerimônia cristã (o casamento), e é este que possibilita a

\footnotetext{
${ }^{1}$ ASSIS, Memórias póstumas de Brás Cubas, p. 46.

2 NIETZSCHE, Genealogia da moral, p. 50-52.

${ }^{3}$ CALDWELL, O Otelo brasileiro de Machado de Assis, p. 38.

${ }^{4}$ SANTIAGO, Retórica da verossimilhança, p. 126.
} 
constituição da família. É, pois, o universo do amor machadiano asséptico, formal, são, rígido. É ainda masculina e burguesa a sua concepção de casamento. Qualquer invasão estranha nesta propriedade - amante - acarreta um curto-circuito emocional que invalida os dois primeiros termos. ${ }^{5}$

Na mesma sintonia, Gledson avalia que, seja qual for a "verdade" acerca do adultério, podemos considerar que o romance é um estudo sobre o ciúme de Bento e as condições que o produzem. Tais condições são, com efeito, idênticas àquelas que fizeram com que o casamento se realizasse. A fim de se casar com Bento, Capitu precisou manipulá-lo e dominá-lo, procedimento que, invertendo os papéis tradicionais do homem e da mulher, provocou ciúme e ressentimento no marido:

Do ponto de vista psicológico, Bentinho é apenas um menino mimado, habituado a que lhe façam as vontades, e possui a incapacidade da criança mimada para compreender que os outros têm uma existência independente da sua, de modo que quando eles afirmam sua independência, como é natural na ordem das coisas, essa afirmação lhe parece traição. ${ }^{6}$

O ciúme doentio de Bento, resultado da sua própria inexperiência decorrente da recusa da mãe superprotetora a deixá-lo crescer normalmente -, funciona como defesa contra o terror do que não pode controlar. Em suma, ainda que a ambiguidade estrutural do romance deixe a questão do adultério em aberto, precisamos levar a sério o drama dos ciúmes do narrador, homem emocionalmente abalado que se crê vítima da mulher amada e do melhor amigo.

O ciúme de Bentinho em relação a Capitu surge pela primeira vez aos quinze anos de idade, antes mesmo de a moça ter notícia da existência de Escobar, ou ele dela. Com toda a sua força e horripilância, o protagonista deseja enterrar as unhas na garganta de Capitu e observar o sangue refluir até a morte dela. Porém, Bento espera mais quinze anos para desfrutar de sua vingança, então sem derramamento de sangue.

A primeira cena de ciúme é relatada no capítulo não por acaso intitulado "Uma ponta de Iago", que narra uma visita de José Dias a Bentinho no seminário, em 1858. O rapaz pergunta ao agregado como vai Capitu, ao

\footnotetext{
${ }^{5}$ Idem, p. 127.

${ }^{6}$ GLEDSON, Machado de Assis: impostura e realismo, p. 12.
} 
que este - com malícia - responde de tal forma que provoca desvarios no jovem Santiago:

- Tem andado alegre, como sempre; é uma tontinha. Aquilo, enquanto não pegar algum peralta da vizinhança, que case com ela...

Estou que empalideci; pelo menos, senti correr um frio pelo corpo todo. A notícia de que ela vivia alegre, quando eu chorava todas as noites, produziu-me aquele efeito, acompanhado de um bater de coração, tão violento, que ainda agora cuido ouvi-lo. [...] Não esqueças que era a emoção do primeiro amor. Estive quase a perguntar a José Dias que me explicasse a alegria de Capitu, o que é que ela fazia, se vivia rindo, cantando ou pulando, mas retive-me a tempo, e depois outra ideia...

Outra ideia, não, - um sentimento cruel e desconhecido, o puro ciúme, leitor das minhas entranhas. Tal foi o que me mordeu, ao repetir comigo as palavras de José Dias: "Algum peralta da vizinhança". Em verdade, nunca pensara em tal desastre. Vivia tão nela, dela e para ela, que a intervenção de um peralta era como uma noção sem realidade; nunca me acudiu que havia peraltas na vizinhança, vária idade e feitio, grandes passeadores das tardes. Agora lembrava-me que alguns olhavam para Capitu - e tão senhor me sentia dela que era como se olhassem para mim, um simples dever de admiração e de inveja. Separados um do outro pelo espaço e pelo destino, o mal aparecia-me agora, não só possível, mas certo. [...] compreenderás que eu, depois de estremecer, tivesse um ímpeto de atirar-me pelo portão fora, descer o resto da ladeira, correr, chegar à casa do Pádua, agarrar Capitu e intimar-lhe que me confessasse quantos, quantos, quantos já lhe dera o peralta da vizinhança. Não fiz nada. Os mesmos sonhos que ora conto não tiveram, naqueles três ou quatro minutos, esta lógica de movimentos e pensamentos. Eram soltos, emendados e mal emendados, com o desenho truncado e torto, uma confusão, um turbilhão, que me cegava e ensurdecia. ${ }^{7}$

Para os nossos propósitos, basta destacar que José Dias plantou a semente do ciúme, que se enraizou na mente de Bentinho e posteriormente frutificou como a certeza do adultério. Cego e ensurdecido por seus sonhos mal emendados, Bento cultivou o ressentimento e tornou-se o escritor Dom Casmurro. O enciumado Santiago, ao que parece, incapaz de esquecer a dor da suposta traição de Capitu e Escobar, escreveu suas memórias para expor

${ }^{7}$ ASSIS, Dom Casmurro, p. 151-152, grifos meus. 
sua ideia fixa ao mundo. Por quê? Porque a dor da ideia fixa é uma espécie de verme roedor interno que ele precisa externar, já que não consegue esquecer:

Como fazer no bicho-homem uma memória? [...] Esse antiquíssimo problema, pode-se imaginar, não foi resolvido exatamente com meios e respostas suaves; talvez nada exista de mais terrível e inquietante na pré-história do homem do que a sua mnemotécnica: "Grava-se algo a fogo, para que fique na memória: apenas o que não cessa de causar dor fica na memória" - eis um axioma da mais antiga (e infelizmente mais duradoura) psicologia da terra. ${ }^{8}$

Essa mnemotécnica da dor teria origem na capacidade humana de fazer promessas. Sendo o esquecimento uma característica constitutiva do homem, e benéfica, por ser a zeladora de nossa ordem psíquica, a faculdade da memória apresenta-se em determinados casos, quando o esquecimento deve ser suspenso - particularmente nos casos em que se deve prometer: "é preciso construir uma memória naquele que promete",, 9 observa Nietzsche. $\mathrm{E}$ Bentinho, um promesseiro notório, andava carregado de promessas não cumpridas: prometeu a Capitu que não iria para o seminário (capítulo XVIII); prometeu rezar dezenas, centenas e milhares de padre-nossos e avemarias (XX e LXVII); prometeu à esposa uma vida sossegada e bela, na roça ou fora da cidade (XLIX); prometeu a Deus que não faria mais promessas que não pudesse pagar, e pagaria logo as que fizesse (LXIX); jurou que nunca mais suspeitaria da infidelidade de Capitu (LXXVI); prometeu não comprar mais nenhuma joia cara para a esposa, mas foi só por pouco tempo (CV).

Se promessa é dívida, como diz o ditado popular - teoricamente fundamentado por Nietzsche em Genealogia da moral -, necessita-se que o devedor se recorde de sua obrigação moral. Entretanto, há um momento a partir do qual a consciência de ter dívidas identifica-se com a má consciência moral. A noção de culpa volta-se para trás e, entrelaçada à má consciência, corrói o interior daquele que se sente culpado:

Cogitei muito no modo de resgatar a divida espiritual. Não achava outra espécie em que, mediante a intenção, tudo se cumprisse, fechando a escrituração da minha consciência moral sem déficit. Mandar dizer cem missas, ou subir de joelhos a ladeira da Glória para ouvir uma, ir à Terra Santa, tudo o que as velhas escravas me contavam de promessas

\footnotetext{
${ }^{8}$ NIETZSCHE, Genealogia da moral, p. 50, grifos do autor.

${ }^{9}$ Idem, p. 53.
} 
célebres, tudo me acudia sem se fixar de vez no espírito. Era muito duro subir uma ladeira de joelhos; devia feri-los por força. A Terra Santa ficava muito longe. As missas eram numerosas, podiam empenhar-me outra vez a alma. ${ }^{10}$

A sutil e dissimulada agressividade de Bento contra as autoridades inatacáveis - Deus e Dona Glória - é inicialmente deslocada para dentro, internalizada, e posteriormente externalizada, voltando-se contra Capitu. Nesse sentido, mesmo que a recordação seja dolorosa, o livro Dom Casmurro propicia ao seu autor a satisfação de fazer sofrer, o prazer de ultrajar Capitu e Escobar - o que ele denominou prazer das dores velhas:

Contando aquela crise do meu amor adolescente, sinto uma coisa que não sei se explico bem, e é que as dores daquela quadra, a tal ponto se espiritualizaram com o tempo, que chegam a diluir-se no prazer. Não é claro isto, mas nem tudo é claro na vida ou nos livros. A verdade é que sinto um gosto particular em referir tal aborrecimento, quando é certo que ele me lembra outros que não quisera lembrar por nada. ${ }^{11}$

No limite, a dívida resgata-se com dor, porque a dor do devedor é prazer para o credor: "a satisfação de quem pode livremente descarregar seu poder sobre um impotente", ${ }^{12}$ diria Nietzsche. Revela-se, assim, a crueldade que se volta para trás, isto é, o ressentimento, tema da próxima seção.

\section{Ressentimento: a crueldade que se volta para trás}

Kathrin Rosenfield avalia que há na obra machadiana "uma nítida nota de ressentimento, cuja encarnação é o nome Dom Casmurro". ${ }^{13}$ Segundo a pesquisadora, no acanhamento tímido do personagem-narrador desaparece a transgressão positiva ou passional e, no lugar de uma ação fatal, surge a entrega passiva ao que é dado - o gosto indulgente da repetição e o ressentimento. Rosenfield avalia que no mar de ponderações do narrador enciumado não há mais espaço nenhum para a ação e a paixão - tudo se torna reação e ressentimento, como podemos observar na maliciosa e irônica cena da descoberta do amor, que se revela a Bentinho não na própria cena do

${ }^{10}$ ASSIS, Dom Casmurro, p. 77, grifo meu.

${ }^{11}$ Idem, p. 150, grifos meus.

12 NIETZSCHE, Genealogia da moral, p. 54.

${ }^{13}$ ROSENFIELD, A ironia de Machado em Dom Casmurro, p. 75. 
beijo e da graciosa entrega de Capitu, mas na denúncia de José Dias. Outrossim, a prosa mostra que não há nada de romântico, belo ou espontâneo no amor de Bento, que permanece uma veleidade frágil, débil querer, à mercê das vontades e das opiniões alheias, conduzindo-o ao ciúme e ao ressentimento:

Machado esboça o complicado labirinto do ressentimento, que desvia as paixões ingênuas para alvos secundários e, assim, as desperdiça. Inação, dúvida, timidez - eis os "traidores" que nos fazem perder "os bens que poderíamos ganhar", substituindo-lhes os sentimentos reativos, "formações secundárias" segundo Freud, que, aqui, tomam as formas convencionais do enfado, da misantropia, do pessimismo vulgar. No ciúme deslocado - tanto no tempo como no espaço - canalizam-se múltiplas cobiças e invejas, impulsos e medos, que a timidez impediu de formular. ${ }^{14}$

Oscilando entre o rancor do mal-amado e os elãs românticos dos bemamados, o narrador casmurro suprime a verdade (seja ela qual for), asfixiando a alma e a ação nos nebulosos fantasmas do ressentimento, afirma Rosenfield. Assim, revela os traços psicológicos de sua passividade insuperável.

Tendo em vista que mesmo um exame cuidadoso dificilmente permitiria mapear todas as variáveis presentes no conceito de ressentimento, deixo de lado as implicações psicanalíticas desta economia psíquica, para resgatar o conceito filosófico de ressentimento apresentado por Nietzsche. Segundo o filósofo, o ressentido procura, sem entender sua natureza endógena, uma causa fora de si para o seu sofrimento, para descarregar contra ela o seu próprio ressentimento e mitigar a dor através de uma intensa reação que julga e despotencializa a vida.

Dom Casmurro seria um homem do ressentimento, sujeito refém de seu passado e de suas marcas, vingativo no limite da exaustão ou da doença, desprovido daquela que seria a autêntica ação, a afirmativa, restando-lhe somente a reação, que consiste numa espécie de autoenvenenamento que o devora por dentro. Impotente quanto ao que foi feito, ele é um irritado espectador de tudo o que passou:

Em linhas gerais, o ressentimento pode ser entendido como uma indigestão psíquica, um tipo de envenenamento produzido quando um

${ }^{14}$ Idem, p. 83, grifo meu. 
indivíduo se mostra incapaz de descarregar o rancor oriundo de uma adversidade ou agressão. Corresponde, assim, a um quantum de força que, não podendo ser lançado para fora, volta-se para o interior do homem onde, sem ser assimilado psiquicamente, continua sendo resentido como um pedaço do passado não digerido que o impede de viver o presente de forma plena. ${ }^{15}$

A palavra de origem francesa ressentiment aparece pela primeira vez nos escritos de Nietzsche em um comentário à obra $O$ valor da vida, de Eugen Dühring: "O sentimento de justiça é um ressentimento, ao qual copertence a vingança". ${ }^{16}$ Nesse texto, Nietzsche assume a concepção de ressentimento utilizada pelo professor berlinense, enquanto sentimento reativo no qual predomina a sede de vingança, e do qual se originaria o sentimento de justiça. ${ }^{17}$

Nos livros publicados por Nietzsche em vida, o conceito de ressentimento aparece pela primeira vez em Genealogia da moral (1887), no qual assume importante papel em sua crítica à moral. Desde então o autor usa o conceito com certa regularidade, como, por exemplo, em $O$ crepúsculo dos ídolos (1888), Ecce homo (1888) e O Anticristo (1895). Na maioria das vezes o filósofo alemão mantém o sentido conferido ao termo na Genealogia, tendo em vista de forma especial a sua associação com a "moral do ressentimento", isto é, uma reatividade e uma impossibilidade de esquecer os agravos sofridos, que culminam em um não mais querer esquecê-los:

Pois todo sofredor busca instintivamente uma causa para seu sofrimento; mais precisamente, um agente; ainda mais especificamente, um agente culpado suscetível de sofrimento - em suma, algo vivo, no qual possa sob algum pretexto descarregar seus afetos, em ato ou in effigie [simbolicamente]: pois a descarga de afeto é para o sofredor a maior tentativa de alívio, de entorpecimento, seu involuntariamente ansiado narcótico para tormentos de qualquer espécie. Unicamente nisto, segundo minha suposição, se há de encontrar a verdadeira causação fisiológica do ressentimento, da vingança e quejandos, ou seja, em um desejo de entorpecimento da dor através do afeto. ${ }^{18}$

\footnotetext{
${ }^{15}$ PASCHOAL, O ressentimento como um fenômeno social, p. 189.

${ }^{16}$ NIETZSCHE, Nachgelassene Fragmente 1875-1879, p. 176, tradução minha.

17 A partir de 1887, Nietzsche apresenta tese oposta à de Dühring, avaliando que a justiça tem sua origem no forte e não em sentimentos reativos como o ressentimento. Ver: BRUSOTTI, Ressentimento e vontade de nada.

${ }^{18}$ NIETZSCHE, Genealogia da moral, p. 116, grifos do autor.
} 
A segunda dissertação de Genealogia da moral oferece a psicologia da consciência: esta não seria, como se crê, a voz de Deus no homem, mas sim o instinto de crueldade que se volta para trás, quando já não pode descarregarse para fora. A crueldade pela primeira vez revelada como um dos mais antigos e indeléveis substratos da cultura.

A crueldade de Bento revela-se em vários episódios. O primeiro é o relato de seu desejo - motivado por uma simples dor de cabeça - de que o trem da Central estourasse longe dos seus ouvidos e "interrompesse a linha por muitas horas, ainda que morresse alguém". ${ }^{19}$ Essa hybris, escolha consciente e voluntária da violência, baseada numa recusa definitiva e inapelável à autoridade da razão, ao revelar um colapso ético, é niilista. Acreditando que pode tudo, o personagem-narrador não tem qualquer parâmetro ético a presidir a sua escala de valores e a orientar suas ações.

O segundo episódio ocorre quando Bentinho voltava de um encontro com Capitu e foi interrompido no caminho pelo pai do pobre menino Manduca, que acabara de falecer em decorrência de hanseníase. Aos prantos o homem conduz o protagonista para dentro de sua loja, a fim de lhe mostrar o filho morto:

Custa-me dizer isto, mas antes peque por excessivo que por diminuto. Quis responder que não, que não queria ver o Manduca, e fiz até um gesto para fugir. Não era medo; noutra ocasião pode ser até que entrasse com facilidade e curiosidade, mas agora ia tão contente! Ver um defunto ao voltar de uma namorada... Há coisas que se não ajustam nem combinam. A simples notícia era já uma turvação grande. As minhas ideias de ouro perderam todas a cor e o metal para se trocarem em cinza escura e feia, e não distingui mais nada. [...] Não culpo ao homem; para ele, a coisa mais importante do momento era o filho. Mas também não me culpem a mim; para mim, a coisa mais importante era Capitu. O mal foi que os dois casos se conjugassem na mesma tarde, e que a morte de um viesse meter o nariz na vida do outro. Eis o mal todo. Se eu passasse antes ou depois, ou se o Manduca esperasse algumas horas para morrer, nenhuma nota aborrecida viria interromper as melodias da minha alma. Por que morrer exatamente há meia hora? Toda hora é apropriada ao óbito; morre-se muito bem às seis ou sete horas da tarde. ${ }^{20}$

Esse discurso do narrador o aproxima do Humanitismo, doutrina que sugere uma impiedosa corrosão ética do trato social, ligando-se aos temas da

${ }^{19}$ ASSIS, Dom Casmurro, p. 163.

${ }^{20}$ Idem, p. 158-159. 
reificação (transformação do homem em objeto do homem), do egoísmo e do sadismo. Parafraseando Quincas Borba: ao vencido (Manduca), ódio ou desprezo; ao vencedor (Bentinho), a namorada. ${ }^{21}$

No capítulo CXXXIV Bento compra um veneno com o intuito de se suicidar. No CXXXVI ele dissolve a droga no café que iria beber, mas é tomado por devaneios e hesita. A porta se fecha para o seu "niilismo suicida"22 e ele coloca seu sofrimento sob a perspectiva da culpa - de Capitu. Por isso, no capítulo seguinte, fremente de vingança, ele tem um segundo impulso e oferece a bebida envenenada ao filho que ele julga ser bastardo:

Se eu não olhasse para Ezequiel, é provável que não estivesse aqui escrevendo este livro, porque o meu primeiro ímpeto foi correr ao café e bebê-lo. Cheguei a pegar na xícara, mas o pequeno beijava-me a mão, como de costume, e a vista dele, como o gesto, deu-me outro impulso que me custa dizer aqui; mas vá lá, diga-se tudo. Chamem-me embora assassino; não serei eu que os desdiga ou contradiga; o meu segundo impulso foi criminoso. Inclinei-me e perguntei a Ezequiel se já tomara café.

- Já, papai; vou à missa com mamãe.

- Toma outra xícara, meia xícara só.

- E papai?

- Eu mando vir mais; anda, bebe!

Ezequiel abriu a boca. Cheguei-lhe a xícara, tão trêmulo que quase a entornei, mas disposto a fazê-la cair pela goela abaixo, caso o sabor lhe repugnasse, ou a temperatura, porque o café estava frio... Mas não sei que senti que me fez recuar. Pus a xícara em cima da mesa, e dei por mim a beijar doidamente a cabeça do menino.

- Papai! papai! - exclamava Ezequiel.

- Não, não, eu não sou teu pai! ${ }^{23}$

A cena revela um conflito interior que se estabelece a partir do confronto entre as ações realizadas e certos pressupostos morais idealizados por seu autor. Seu lado bento domina a situação, reprime o seu instinto de vingança e promove a má consciência. Anos mais tarde, Santiago defronta-se com sua própria má consciência e livra-se de seu sentimento de culpa. Assim, com espírito e boa consciência, ele deseja novamente a morte de Ezequiel que, meses depois, falece. $\mathrm{E}$ após receber a notícia da morte do filho por

\footnotetext{
21 “Ao vencido, ódio ou compaixão; ao vencedor, as batatas.” ASSIS, Quincas Borba, p. 56.

22 NIETZSCHE, Genealogia da moral, p. 149.

${ }^{23}$ ASSIS, Dom Casmurro, p. 262.
} 
febre tifoide - não por lepra, como havia desejado - o narrador janta bem e vai ao teatro:

Não houve lepra, mas há febres por todas essas terras humanas, sejam velhas ou novas. Onze meses depois, Ezequiel morreu de uma febre tifoide, e foi enterrado nas imediações de Jerusalém, onde os dois amigos da universidade lhe levantaram um túmulo com esta inscrição, tirada do profeta Ezequiel, em grego: "Tu eras perfeito nos teus caminhos". Mandaram-me ambos os textos, grego e latino, o desenho da sepultura, a conta das despesas e o resto do dinheiro que ele levava; pagaria o triplo para não tornar a vê-lo. ${ }^{24}$

Essa passagem é mais uma manifestação do amoralismo e do despotismo do menino mimado convertido em casmurro, que mostra que a moral não serve de arrimo para nada e não leva a nada. Mas se esse comportamento indica crueldade e niilismo, ainda não é a demonstração da "crueldade voltada para trás", ${ }^{25}$ que se revela na redação da própria obra Dom Casmurro.

Bento Santiago escreve motivado por ressentimento, com a sua vontade voltada para trás, pois o ressentimento, antes de ser uma forma de ação proativa (que tem sua origem nela mesma), é uma reação que se produz como resposta a uma agressão que não pode ser revidada de forma imediata.

O ressentido precisa de outro para existir, o seu inimigo mau, o culpado pelo seu sofrimento - alguém deve ser culpado por sua existência. Nietzsche, quando descreve a maneira de raciocinar comum aos ressentidos que desconhecem a verdadeira causa do seu mal-estar, parece referir-se ao velho Bento Santiago:

Os sofredores são todos horrivelmente dispostos e inventivos, em matérias de pretextos para seus afetos dolorosos; eles fruem a própria desconfiança, a cisma com baixezas e aparentes prejuízos, eles revolvem as vísceras de seu passado e seu presente, atrás de histórias escuras e questionáveis, em que possam regalar-se em uma suspeita torturante, e intoxicar-se do próprio veneno de maldade - eles rasgam as mais antigas feridas, eles sangram de cicatrizes há muito curadas, eles transformam em malfeitores o amigo, a mulher, o filho e quem mais

\footnotetext{
${ }^{24}$ Idem, p. 275.

${ }^{25}$ NIETZSCHE, Genealogia da moral, p. 129.
} 
lhe for próximo. "Eu sofro: disso alguém deve ser culpado" - assim pensa toda ovelha doente. ${ }^{26}$

Em um fragmento póstumo do outono de 1888, Nietzsche caracteriza o ressentimento justamente como "raiva, desejo de vingança - o mais prejudicial de todos os estados possíveis para o doente" ${ }^{27} \mathrm{O}$ fato é que a vingança do ressentido, justamente por ter de esperar, tem um efeito muito mais eficaz e destrutivo do que aquela vingança que se tem como uma reação imediata. Primeiro, porque àquele quantum de força inicialmente interiorizado pela ofensa sofrida somam-se inúmeras novas injúrias reais e imaginárias e, segundo, porque a própria vingança pode ser mais bem calculada e planejada.

Como diz o ditado, a vingança é um prato que se come frio. E Bento seguiu a lição à risca, aguardando o momento mais oportuno para agir - ele esperou a morte de Escobar. Com a morte do amigo, o protagonista desconsidera qualquer laço de amizade. Cegado pelo ciúme, ao amigo morto sequer é concedido o benefício da dúvida. Sufocado pelo ressentimento, o protagonista se dedica a destruir todos à sua volta, inclusive a si mesmo.

Ao propor a separação, Bento disse a Capitu que "cada um iria com a sua ferida". ${ }^{28}$ Mas, não satisfeito com o afastamento, a crueldade internalizada do seu ressentimento foi lentamente sublimada na forma da corte judiciária, que julgou, condenou e castigou Capitu, pois "em matéria de culpa a graduação é infinita". ${ }^{29}$

Insatisfeito com o julgamento sem direito a defesa e a punição sumária, Bento escreve suas memórias sob o domínio das forças reativas, para defender sua tese ao grande público. Depois de persuadir a si mesmo, transformando o possível em certeza e o verossímil em verdade, ele quer advogar em causa própria e persuadir o leitor. Por isso, ele é um autor que escreve e simultaneamente interpreta o texto para os leitores.

Bento ignora que os únicos antídotos para o ressentimento são a reação imediata e o perdão (remissão da ofensa ou da dívida), fatores que permitem às naturezas fortes e plenas sacudirem para longe de si "muitos vermes que em outros, ao contrário, se enterrariam". ${ }^{30} \mathrm{Ou}$, ainda, o esquecimento ativo, capaz de livrar a consciência das amarras do ressentimento, "Pois sadio é

\footnotetext{
${ }^{26}$ Idem, p. 117.

${ }^{27}$ NIETZSCHE, Nachgelassene Fragmente 1887-1889, p. 618, tradução minha.

${ }^{28}$ ASSIS, Dom Casmurro, p. 264.

${ }^{29}$ Idem, p. 185.

30 NIETZSCHE, Genealogia da moral, p. 31.
} 
quem esquece". ${ }^{31}$ Esquecer, nesse sentido, não equivaleria ao movimento secundário e passivo de um bloqueio de memória provocado por trauma, que levaria a um esquecimento de si. O esquecimento ativo, ao invés de apagar as marcas já produzidas pela memória, antecipa-se a elas, impedindo qualquer fixação negativa. Esse esquecimento entendido como derivado de uma força plástica e modeladora propiciaria a Bento desaprender o espírito de vingança contra o tempo e desejar o "foi", o "é" e o "será".

Justamente por ser um ressentido notório - incapaz de redenção e esquecimento - o aristocrata escritor revela sua própria fraqueza. Apresentando-se como um senhor respeitável, honesto, intelectual e vítima de traição, ironicamente ele se mostra um sujeito mimado, vaidoso, dissimulado, ciumento e ressentido. Diante da impossibilidade de recuperar o tempo perdido, a nostalgia desse narrador de si mescla o passado com o presente e desloca qualquer sentido de futuro. Ao revolver o passado, Bento Santiago expressa falta de plenitude, sentimento de abandono e um espírito de vingança contra o tempo.

\section{Referências}

ASSIS, Machado de. Memórias póstumas de Brás Cubas. Fixação de texto e notas de Marcelo Módolo; prefácio de Abel Barros Baptista. São Paulo: Globo, 2008.

Quincas Borba. Fixação de texto e notas de Eugênio Vinci de Moraes; prefácio de Willi Bolle. São Paulo: Globo, 2008.

Dom Casmurro. Fixação de texto e notas de Manoel Mourivaldo Santiago Almeida; prefácio de John Gledson. São Paulo: Globo, 2008.

BRUSOTTI, Marco. Ressentimento e vontade de nada. Cadernos Nietzsche, n. 8, 2000, p. 3-34.

CALDWELL, Helen. O Otelo brasileiro de Machado de Assis: um estudo de Dom Casmurro. Tradução de Fábio Fonseca de Melo. Cotia, SP: Ateliê Editorial, 2008.

GLEDSON, John. Machado de Assis: impostura e realismo. Tradução de Fernando Py. São Paulo: Companhia das Letras, 1991.

NIETZSCHE, Friedrich Wilhelm. Genealogia da moral: uma polêmica. Tradução de Paulo César de Souza. São Paulo: Companhia das Letras, 1998.

Nachgelassene Fragmente 1875-1879. In: Sämtliche Werke. Kritische

Studienausgabe. Herausgegeben von Giorgio Colli und Mazzino Montinari. Berlin, New York: de Gruyter, 1999, v. 8.

${ }^{31}$ NIETZSCHE, A Gaia Ciência, p. 19. 
Nachgelassene Fragmente 1887-1889. In: Sämtliche Werke. Kritische Studienausgabe. Herausgegeben von Giorgio Colli und Mazzino Montinari. Berlin, New York: de Gruyter, 1999, v. 13.

- A Gaia Ciência. Tradução de Paulo César de Souza. São Paulo: Companhia das Letras, 2001.

. Crepúsculo dos ídolos, ou, como se filosofa com o martelo. Tradução de Paulo César de Souza. São Paulo: Companhia das Letras, 2006.

O Anticristo: maldição ao cristianismo. Tradução de Paulo César de Souza. São Paulo: Companhia das Letras, 2007.

Ecce Homo: como alguém se torna o que é. Tradução de Paulo César de Souza. São Paulo: Companhia de Bolso, 2011.

PASCHOAL, Antonio Edmilson. O ressentimento como um fenômeno social. In: BARRECHENEA, Miguel Angel de et al. (Org.). Nietzsche e as ciências. Rio de Janeiro: 7 Letras, 2001, p. 189-201.

ROSENFIELD, Kathrin Holzermayr. A ironia de Machado em Dom Casmurro: reflexões sobre a cordialidade antitrágica. Letras, Santa Maria, v. 32, p. 71-90, 2007.

SANTIAGO, Silviano. Retórica da verossimilhança. In: ASSIS, Machado de. Obra completa, em quatro volumes: volume 1. Rio de Janeiro: Nova Aguilar, 2008, p. 125138.

VITOR CEI é doutor em Teoria da Literatura e Literatura Comparada pela Universidade Federal de Minas Gerais, com a tese intitulada $A$ voluptuosidade do nada: o niilismo na prosa de Machado de Assis (2015). Atualmente é professor do curso de licenciatura em Filosofia da SEAD-UFES e membro do conselho editorial de Outramargem: Revista de Filosofia. Tem no prelo o livro Brasil em crise (Editora Praia). E-mail: vitorcei@gmail.com.

Recebido: 08.03.2015

Aprovado: 27.04.2015 